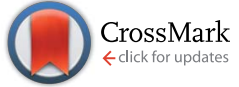

Cite this: RSC Adv., 2017, 7, 11030

Received 26th November 2016 Accepted 6th February 2017

DOI: 10.1039/c6ra27376a

rsc.li/rsc-advances

\section{Study on the synthesis and tribological properties of anti-corrosion benzotriazole ionic liquid $\dagger$}

\author{
S. Zhang, ${ }^{a}$ L. Ma, ${ }^{a}$ R. Dong, ${ }^{a}$ C. Y. Zhang, ${ }^{a}$ W. J. Sun, ${ }^{a}$ M. J. Fan, ${ }^{\star a}$ D. S. Yang, ${ }^{\text {*a }}$ F. Zhou ${ }^{b}$ \\ and W. M. Liu
}

Anti-corrosion benzotriazole ionic liquid (IL, BTAP 4444 ) was synthesized by neutralizing $1 \mathrm{H}$-benzotriazole (BTAH) with terabutylphosphonium hydroxide $\left(\mathrm{P}_{4444} \mathrm{OH}\right)$. The physicochemical and tribological properties of $\mathrm{BTAP}_{4444}$ were measured and the results indicated that it had good lubricating properties for steel/steel, steel/copper and steel/aluminum friction pairs in reducing the friction coefficient and wear volume, especially when it worked for the steel/copper friction pair both at room temperature (RT) and $100{ }^{\circ} \mathrm{C}$. Good performances were also found in terms of its anti-corrosion ability, thermal and hydrolysis stability, and viscosity temperature characteristics compared with commercially available synthetic oil poly-alpha-olefin (PAO 10) and traditional IL 1-butyl-3-methyl imidazolium tetrafluoroborate $\left(\right.$ bmimBF$\left._{4}\right)$. The designing purpose of $\mathrm{BTAP}_{4444}$ is to enhance the anti-corrosion ability of the IL lubricant attributed to the introduction of a nitrogen heterocyclic structure, $1 \mathrm{H}$-benzotriazole, which is normally used as antirust and corrosion inhibitor in mechanical engineering. The corrosion test results confirm our assumption and $\mathrm{BTAP}_{4444}$ shows excellent anti-corrosion ability for all the used friction pairs including steel/steel, steel/copper and steel/aluminum contacts.

\section{Introduction}

Friction is everywhere, whether it is a bicycle, a car, a ship or an aircraft, and there is a phenomenon of friction and wear in the moving parts of mechanical equipment. Therefore, a lubricating oil is needed to reduce friction and wear. However, during long-term mechanical friction, a lubricating oil may degrade and produce some pollutants, which can cause damage to the friction surface. Especially in the presence of oxygen, water, acid or under other harsh conditions, obvious oxidation or corrosion phenomena will occur on the metal friction surface, increasing the mechanical wear and reducing the lubricating performance of a lubricating oil. ${ }^{1}$ Therefore, it is necessary to use lubricating oil with multi-functional properties, such as anti-oxidation, corrosion resistance and so on, to improve energy utilization and material durability.

As is known to all, ionic liquids (ILs) have been used as a kind of high performance lubricants and attracted great attention in recent years. ${ }^{2,3}$ So, what is an IL? It is a salt with melting point below $100{ }^{\circ} \mathrm{C}$ and consists of only cation and anion which are all capable of facile tuning. ${ }^{4-6}$ ILs have some

${ }^{a}$ Shaanxi Key Laboratory of Phytochemistry, College of Chemistry \& Chemical Engineering, Baoji University of Arts and Sciences, Baoji 721013, China. E-mail: mingjinfan@163.com; Fax: +86-9173566000; Tel: +86-9173565561

${ }^{b}$ State Key Laboratory of Solid Lubrication, Lanzhou Institute of Chemical Physics, Chinese Academy of Sciences, Lanzhou 730000, China

$\dagger$ Electronic supplementary information (ESI) available. See DOI: $10.1039 / \mathrm{c} 6 \mathrm{ra} 27376 \mathrm{a}$ excellent physical properties, such as low volatility, nonflammability, low melting point, good viscosity temperature characteristic, large heating capacity, outstanding chemical stability and so on.$^{7-10}$ Because of these excellent characteristics, ILs can be used as high-performance lubricants or lubricant additives for base oil, grease or water, ${ }^{\mathbf{1 1}-16}$ However, when traditional ILs are used as lubricants or lubricant additives, they are often accompanied by corrosion during the process of friction, because most of them contain halogens, such as $\mathrm{BF}_{4}{ }^{-}, \mathrm{PF}_{6}{ }^{-}, \mathrm{X}^{-}$ $\left(\mathrm{F}^{-}, \mathrm{Cl}^{-}, \mathrm{Br}^{-}\right.$, etc. $)$. These halogen containing anions are prone to hydrolyze and generate acid compounds (HX), which erodes the surface of friction pairs. ${ }^{17}$ Metal corrosion is a serious problem in industry fields. ${ }^{18,19}$ It has attracted particular attention, and the protection of metal and its alloys is of paramount important. ${ }^{18}$ There are two ways to solve the problem of corrosion. One is completely avoiding the using of halogen containing anion. For example, the use of amino acid, tricyanomethanide, dicyanamide, and chelated orthoborate anion-based ILs. ${ }^{\mathbf{2 0 - 2 5}}$ Although these ILs have low corrosion ability, their thermal stability is found to be poor. Besides, their synthesis procedure is still complex, therefore, it hinders its potential application. ${ }^{26}$ Another way to avoid corrosion is adding preservatives or introducing a functional group with corrosion resistance to original IL molecules. For example, reduce corrosion by using $1 \mathrm{H}$-benzotriazole (BTAH) as a preserving additive. Since the first report of BTAH in 1947, it has attracted much attention as a corrosion inhibitor in different applications. ${ }^{27-31}$ BTAH and its derivatives were found to be effective 
corrosion inhibitors to various metals, such as copper, mild steel, etc. because of its unique space structure..$^{32-39}$ Furthermore, BTAH is found to be the most effective copper corrosion inhibitors among BTAH and other two benzotriazole derivatives, 1-hydroxybenzotriazole (BTAOH) and 3-amino-1,2,4triazole (ATA). ${ }^{18,40,41}$ However, free BTAH is not stable enough at high temperature, and its thermal decomposition temperature is only about $150{ }^{\circ} \mathrm{C}$. At the same time, it has limited sublimation temperature of $98 \sim 99^{\circ} \mathrm{C}$, so BTAH cannot be used as an effective anticorrosive additive to IL lubricants under high temperature condition. ${ }^{42}$ The work of designing new IL molecular which has benzotriazole as a substituted group, such as the synthesis of imidazolium ILs bearing benzotriazole group, were conducted by Cai $e t$ al., but the synthetic process of these ILs are too complicated to be conducted in practical using. ${ }^{43,44}$

As far as we known, the study of directly using BTAH as an anion donor to design new IL lubricants has not been reported. Therefore, in this paper, a new type of anti-corrosion IL BTAP $_{4444}$ was synthesized by using readily available chemicals BTAH and terabutylphosphonium hydroxide $\left(\mathrm{P}_{4444} \mathrm{OH}\right)$ as raw materials, which was found to have good performances in terms of thermal and hydrolysis stability, viscosity temperature characteristic, tribological property and especially anti-corrosion ability.

\section{Experimental}

\subsection{Chemicals and synthesis of the ILs}

Synthetic oil poly-alpha-olefin (PAO 10) was purchased from Exxon Mobil Companies and conventional IL 1-butyl-3-methyl imidazolium tetrafluoroborate $\left(\mathrm{bmimBF}_{4}\right)$ was provided by Lanzhou Institute of Chemical Physics. Other used chemicals were commercially available: benzotriazole $(99 \%, \mathrm{~J} \& \mathrm{~K}), \mathrm{P}_{4444} \mathrm{OH}$ solution ( $40 \%$ in water, Aladdin). IL $\mathrm{BTAP}_{4444}$ was synthesized through an economical and feasible method. The detail process is presented in the ESI. $\dagger$

\subsection{Characterization}

The molecular structure of $\mathrm{BTAP}_{4444}$ was determined by proton nuclear magnetic resonance spectroscopy $\left({ }^{1} \mathrm{H} \mathrm{NMR}, 400 \mathrm{MHz}\right)$, carbon nuclear magnetic resonance spectroscopy $\left({ }^{13} \mathrm{C}\right.$ NMR, $100 \mathrm{MHz}$ ) which were carried on an Agilent $400 \mathrm{MHz}$ nuclear magnetic resonance spectrometer (NMR) by using $\mathrm{CDCl}_{3}$ as a solvent and tetramethylsilane (TMS) as an external standard. The high-resolution mass spectra (HRMS) were conducted on an AB SCIEX TOFTM 4600 MS equipped with an electrospray ionization (ESI) probe. The Fourier transform infrared (FT-IR) spectra was recorded on a Nicolet Nexus 670 spectrometer (Thermo Fisher, USA) with wave numbers ranging from 700 $\mathrm{cm}^{-1}$ to $4000 \mathrm{~cm}^{-1}$.

\subsection{Thermal stability}

The thermal stabilities of $\mathrm{BTAP}_{4444}$ and the reference samples (PAO 10, bmimBF 4 and BTAH) were studied on a Netzsch synchronous thermal analyzer system (DSC/DTA-TG, STA 449 F3). The temperature was set up to increase from RT to $600{ }^{\circ} \mathrm{C}$ with a heating rate of $10^{\circ} \mathrm{C} \mathrm{min}^{-1}$. The analysis was conducted

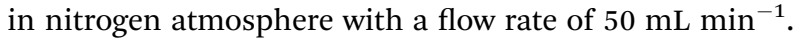

\subsection{Viscosity}

The kinetic viscosities of $\mathrm{BTAP}_{4444}$ and the reference samples (PAO 10 and $\mathrm{bmimBF}_{4}$ ) were measured at $40{ }^{\circ} \mathrm{C}$ and $100{ }^{\circ} \mathrm{C}$ respectively by using a SYP1003-III kinematic viscosity tester. Viscosity indexes of the samples were calculated to evaluate their viscosity temperature characteristics.

\subsection{Hydrolysis stability analysis}

The hydrolysis stabilities of $\mathrm{BTAP}_{4444}$ and the reference samples were measured according to the procedure described in our previous work. ${ }^{45-48}$ Each sample was mixed with equal molar amount of water and then stirred at RT for a certain time. After $30 \mathrm{~min}, 1 \mathrm{~h}, 2 \mathrm{~h}$ until $48 \mathrm{~h}$, their $\mathrm{pH}$ values were measured to indicate their hydrolysis stability. All of the ILs were found to be miscible with water and the mixed solutions were used to measure the $\mathrm{pH}$ value changes. But for PAO 10, because it is not miscible with water, only the water layer of the mixture was used to measure its $\mathrm{pH}$ value changes.

\subsection{Corrosion test}

2.6.1 Copper strip corrosion test. The copper strip corrosion test of $\mathrm{BTAP}_{4444}$ and the reference samples was studied according to the GB-T5096-1985 (91) procedure. The length, width and thickness of the copper strips used in the experiment are $12.0 \mathrm{~mm}, 12.0 \mathrm{~mm}$ and $3.0 \mathrm{~mm}$, respectively. Copper strips were polished with sandpaper, and the surfaces were cleaned with acetone, and dried in air naturally. They were then immersed into the samples, and heated at $100{ }^{\circ} \mathrm{C}$ for $24 \mathrm{~h}$ in an oven. At the end of the test, the copper strips were taken out and washed with acetone thoroughly. The photos of the copper strips were taken and the surface morphologies were analyzed by an FEI Quanta 250 scanning electron microscope (SEM).

2.6.2 Accelerated corrosion test. Configuration of the test solution: a certain amount of a sample was dissolved in $25 \mathrm{~mL}$ methanol, then $25 \mathrm{~mL}$ of saturated calcium hydroxide $\left[\mathrm{Ca}(\mathrm{OH})_{2}\right]$ solution was added to form a $0.01 \mathrm{~mol} \mathrm{~L}^{-1}$ solution (sample concentration). The well-polished steel, copper and aluminum discs were soaked into the prepared solutions which were maintained at RT for a certain time (steel discs: 3 months, copper discs: 10 days, and aluminum discs: 5 days). In addition, the corresponding discs soaked in saturated $\left[\mathrm{Ca}(\mathrm{OH})_{2}\right]$ solution were used as blank comparisons under the same conditions.

\subsection{Friction and wear test}

The tribological properties of $\mathrm{BTAP}_{4444}$ and the reference samples on different friction pairs were evaluated by an Optimol SRV-V oscillating reciprocating friction and wear tester through a reciprocating ball-on-disk configuration test style. The tests were performed both at RT and $100{ }^{\circ} \mathrm{C}$. Before the tests, a drop of a sample was added onto the ball-disc contact area. A AISI 52100 bearing steel ball (diameter $=10 \mathrm{~mm}$, hardness $=59-63 \mathrm{HRC}$, and mean roughness $=100 \mathrm{~nm}$ ) was 
made to slide on a lower stationary disk (ø 24-7.9 mm) with load of $100 \mathrm{~N}$, oscillation frequency of $25 \mathrm{~Hz}$, sliding amplitude of 1 $\mathrm{mm}$ and duration of $30 \mathrm{~min}$. During the tests, environmental humidity was maintained between $30-50 \%$. The lower stationary steel, copper and aluminum discs were made of AISI 52100 bearing steel (hardness $=59-63$ HRC), ZQSn 663 copper (hardness $=140-160 \mathrm{HV}$ ) and 2024 aluminum alloy (hardness $=$ 140-170 HV), respectively. Before the friction and wear tests, the steel, copper, and aluminum disks were polished in turn with 400, 800 and $1500 \mathrm{Cw}$ SiC sandpaper until the mean roughness of the surfaces were about 20-50, 100-200, and 100-200 nm, respectively. The homologous friction curves were recorded automatically by the SRV test rig. After the tests, losses of the wear volumes of different lower discs were measured by using a non-contact surface mapping profiler (BRUKER-NPFLEX). Three times of repeating measurements were carried for each sample, and average values are reported. The element composition and morphology of the worn surfaces were analyzed by using X-ray photoelectron spectroscopy (XPS) which was conducted on an AXIS SUPRA X-ray photoelectric spectrometer manufactured by UK Kratos Company and monochromatic anode $\mathrm{Al}$ target $(\mathrm{Al} \mathrm{K} \alpha 1486.6 \mathrm{eV}$ ) was used as the exciting source. The test condition is: voltage $=15 \mathrm{kV}$, power $=225 \mathrm{~W}$, exit angle $0^{\circ}$ and resolution $= \pm 0.3 \mathrm{eV}$. Before scanning, the worn surfaces were ultrasonic cleaned three times with ethanol. The binding energy of contaminated carbon (C 1s: $284.8 \mathrm{eV}$ ) was used as the reference.

\section{Results and discussion}

\subsection{Structure characterization and thermal stability}

The chemical structures, names and codes of BTAP $_{4444}$, bmimBF$_{4}$, and PAO 10 are given in Table 1 . The structure and purity of $\mathrm{BTAP}_{4444}$ was finely confirmed by ${ }^{1} \mathrm{H}$ NMR, ${ }^{13} \mathrm{C} \mathrm{NMR}$, FT-IR and HRMS spectroscopic data. The detail data are presented in the ESI. $\dagger$

Table 1 The chemical structures, names and codes of the used samples

Samples (code)
Poly-alpha-olefin (PAO 10)

The thermal stabilities of the samples were probed over the temperature range of RT to $600{ }^{\circ} \mathrm{C}$. Fig. 1 shows the thermogravimetry (TG) curves of all the samples. It is clearly seen that $\mathrm{BTAP}_{4444}$ has no rapid weight loss below $300{ }^{\circ} \mathrm{C}$ and the temperature for its total decomposition is higher than $400{ }^{\circ} \mathrm{C}$. The onset decomposition temperature of $\mathrm{BTAP}_{4444}$ is found to be lower than bmimBF$_{4}$ but far higher than that of PAO 10.

For example, about $85 \%$ of PAO 10 was decomposed at $350{ }^{\circ} \mathrm{C}$, but only $20 \%$ of $\mathrm{BTAP}_{4444}$ was decomposed at this temperature. Especially, as compared with raw material BTAH, the thermal decomposition temperature is greatly improved. Neat 1H-benzotriazole has very low thermal decomposition temperature (about $150{ }^{\circ} \mathrm{C}$ ). So, in terms of thermal stability, BTAP $_{4444}$ has a great advantage to be used as a lubricant.

\subsection{Viscosity}

The kinematic viscosities of all the samples were measured at $40{ }^{\circ} \mathrm{C}$ and $100{ }^{\circ} \mathrm{C}$, respectively. According to the test results, viscosity indexes were calculated to evaluate the viscositytemperature characteristics of the samples (Table 2). It is clearly seen that the viscosity of $\mathrm{BTAP}_{4444}$ is far higher than the comparing samples both at $40{ }^{\circ} \mathrm{C}$ and $100{ }^{\circ} \mathrm{C}$. But its viscosity index is relatively low, which is attributed to the molecular structural characteristic of $\mathrm{BTAP}_{4444}$. On the one hand, viscosity index of IL with aromatic ion is lower than that with nonaromatic ion because of the delocalized negative charge on aromatic ion and thus the weaker cation-anion interaction. ${ }^{\mathbf{4 9}}$ On the other hand, viscosity index of phosphonium-based IL with a phosphorus atom in the cationic center are lower than that of ammonium-based IL with a nitrogen atom in the cationic center..$^{\mathbf{5 0 , 5 1}}$

\subsection{Hydrolysis stability analysis}

To affirm the hydrolysis stability of $\mathrm{BTAP}_{4444}$, it was mixed with a same mass of water and then the solution was stirred at RT. The $\mathrm{pH}$ value of the solution was tested periodically to reflect the hydrolysis qualitatively. From Fig. 2, it can be seen that the

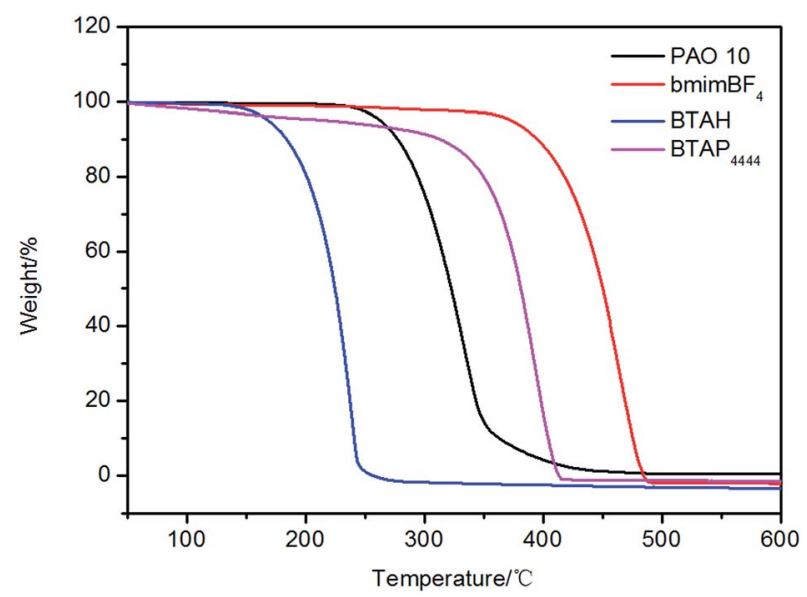

Fig. 1 Thermal decomposition temperatures of PAO 10, bmimBF 4 , $\mathrm{BTAH}$, and $\mathrm{BTAP}_{4444}$ 
Table 2 Viscosities and viscosity indexes of the samples

\begin{tabular}{lrrr}
\hline & \multicolumn{2}{l}{ Kinematic viscosity $\left(\mathrm{mm}^{2} \mathrm{~s}^{-1}\right)$} & \\
\cline { 2 - 3 } Samples & $40{ }^{\circ} \mathrm{C}$ & $100{ }^{\circ} \mathrm{C}$ & $\begin{array}{l}\text { Viscosity } \\
\text { index }\end{array}$ \\
\hline PAO 10 & 68.8835 & 9.4659 & 123.32 \\
bmimBF $_{4}$ & 42.9653 & 7.1201 & 126.60 \\
BTAP $_{4444}$ & 373.1334 & 20.7642 & 54.27
\end{tabular}

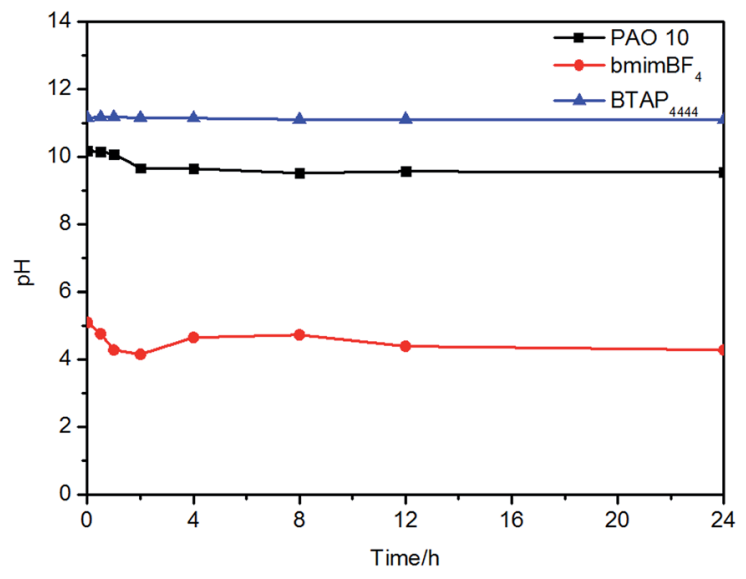

Fig. 2 The $\mathrm{pH}$ change curves of the samples.

hydrolytic stability of bmimBF 4 was relatively poor, whose $\mathrm{pH}$ decreased greatly at the beginning of the experiment (within the first $2 \mathrm{~h}$ ). ${ }^{45}$ Compared with bmimBF 4 , the $\mathrm{pH}$ value of $\mathrm{BTAP}_{4444}$ had almost no change throughout the test. This means that $\mathrm{BTAP}_{4444}$ is stable and not easily hydrolyzed, which has the potential to be used as an efficient lubricant. Under the same condition, the $\mathrm{pH}$ value of PAO 10 did not change during the next $24 \mathrm{~h}$. Above of all, these results indicate that $\mathrm{BTAP}_{4444}$ and PAO 10 have good hydrolysis stability to be used lubricants.

\subsection{Corrosion test}

3.4.1 Copper strip corrosion test. Copper strip corrosion test is adopted to test the corrosion ability of $\mathrm{BTAP}_{4444}$ and the reference samples. $\mathrm{BTAP}_{444}$ was expected to have no corrosion or far less corrosion than traditional ILs.

The photographs of the adopted copper sheets are shown in Fig. 3. It is found that the copper strip immersed in $\mathrm{BTAP}_{4444}$ did not show any color change and remained bright compared with the fresh copper (Fig. 3). The color of the copper strip

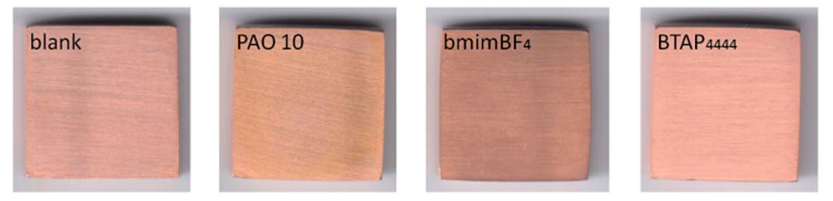

Fig. 3 The photographs of the copper strips adopted during the corrosion tests (blank: a new finished copper strip). immersed in PAO 10 showed only a slight discoloration, while many black points were found on the copper strip immersed in bmimBF$_{4}$. The results indicated that bmimBF $_{4}$ contains halogen and is unstable, so hydrolysis occurred during the corrosion test resulting in the generation of corrosion to the copper strip. However, $\mathrm{BTAP}_{4444}$ has halogen-free characteristic, so there is not corrosion phenomenon occurring on the surface. According to the test results, it also can be seen that $\mathrm{BTAP}_{4444}$ may have anticorrosion property and it is worth to verify. In order to verify the anticorrosion function of $\mathrm{BTAP}_{4444}$, accelerated corrosion experiments were conducted.

3.4.2 Accelerated corrosion test. Accelerated corrosion test was carried in order to confirm the anticorrosion property of $\mathrm{BTAP}_{4444}$. The copper discs (would be used in the following tribological tests) were soaked in saturated $\mathrm{Ca}(\mathrm{OH})_{2}$ solutions containing $0.01 \mathrm{~mol} \mathrm{~L}^{-1}$ of the tested samples and maintained for 10 days. A copper disc immersed in saturated $\mathrm{Ca}(\mathrm{OH})_{2}$ solution (without ILs) was used as a blank control experiment. During the test, BTAH was selected as another comparison to confirm the anticorrosion property of $\mathrm{BTAP}_{4444}$. Table 3 shows the pictures of the copper discs after the test. From Table 3, it can be clearly seen that severe corrosion occurred on the copper discs soaked in the blank and $\mathrm{bmimBF}_{4}$ solutions. Although the copper disc in the solution containing BTAH was corroded very slightly and the copper surface showed little color change, BTAH is a solid and has low thermal stability, so it cannot be used as a lubricant. Table 3 also exhibits the SEM morphologies of the samples. According to the SEM morphologies, it can be seen that the skin layers of the copper discs soaked in the blank and $0.01 \mathrm{~mol} \mathrm{~L}^{-1}$ bmimBF$_{4}$ solutions have been eroded away, and the surface structure of the discs changed obviously. By contrast, slight change occurred on the copper disc surfaces that were soaked in the solutions containing BTAH and $\mathrm{BTAP}_{4444}$. The texture structure of the surface which came from mechanical polishing before the test was clearly seen. These results undoubtedly confirm the anticorrosion property of BTAH and BTAP $_{4444}$ to copper material.

The materials of steel and aluminum have been widely used in industrial production, and in the following experiments they will also be chosen to test the tribological properties of BTAP $_{4444}$. So steel and aluminum discs were also selected to do the accelerated corrosion tests. The corrosion of steel is much slower than that of copper, so the test need a longer time and would be lasted for 3 months. However, due to the soft texture of aluminum, the accelerated corrosion test need a shorter time and would be lasted only for 5 days. The results of the tests are shown in Tables 4 and 5. From Table 4, it can be clearly seen that severe corrosion occurred on the steel discs soaked in the blank and bmimBF ${ }_{4}$ solutions and the surface colors of the steel discs become dark black. The solutions also changed from colorless to deep brown. However, under the same condition, the steel discs immersed in BTAH and BTAP $_{4444}$ solutions show no color change, and the texture structure of the surfaces which came from mechanical polishing before the test can be clearly seen. Also, no color change was found in the solutions. It means that BTAH and $\mathrm{BTAP}_{4444}$ have obvious anticorrosion characteristics for steel discs. The 
Table 3 The photographs and SEM imagines of the copper discs used in the accelerated corrosion tests

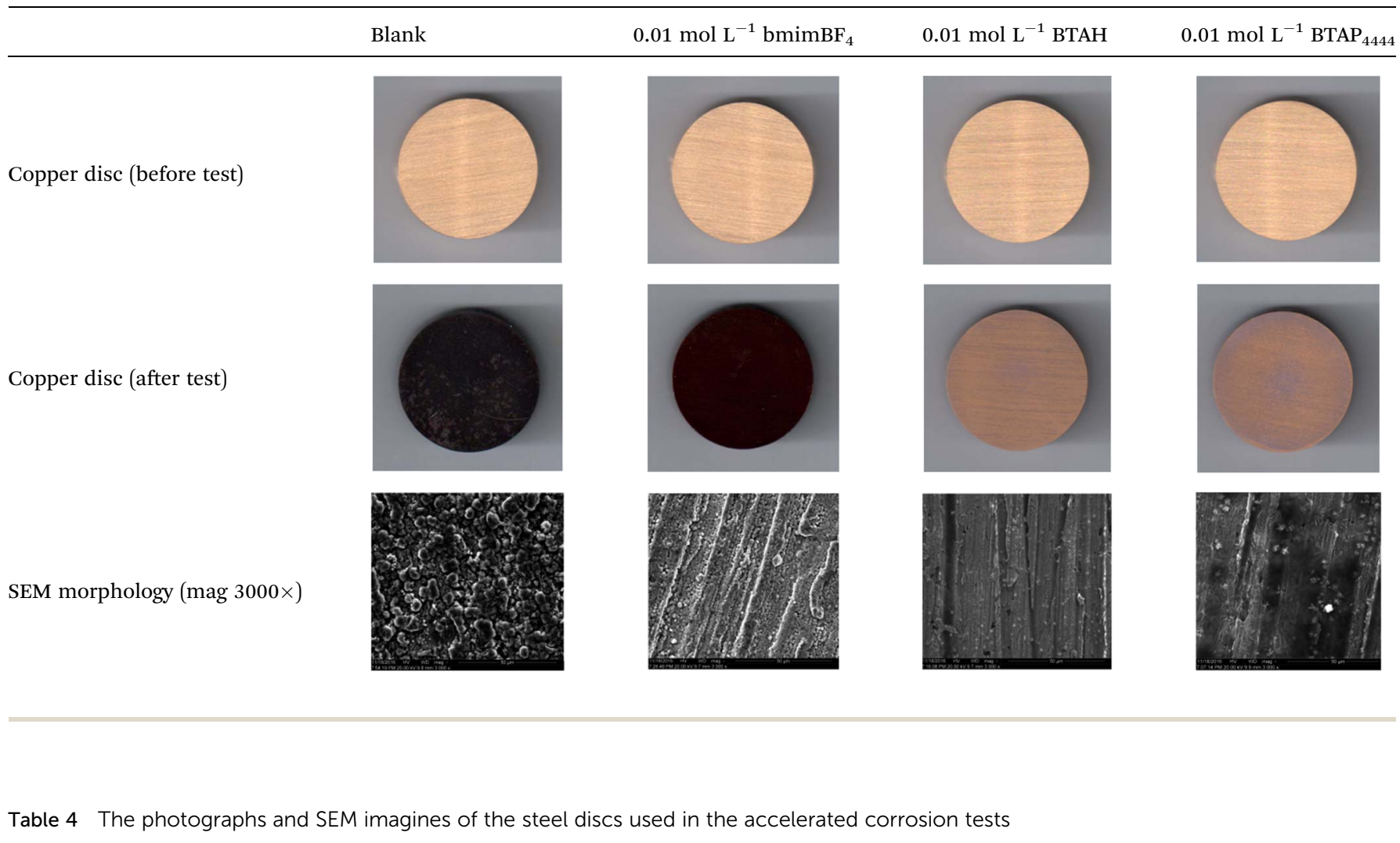

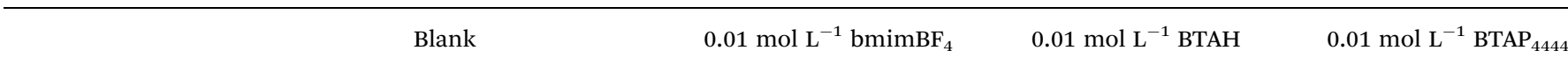

Solution colour

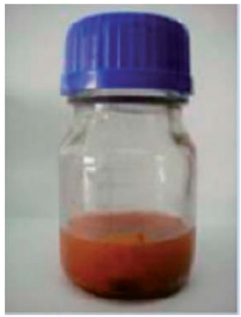

Steel disc (before test)

Steel disc (after test)

SEM morphology (mag $3000 \times)$
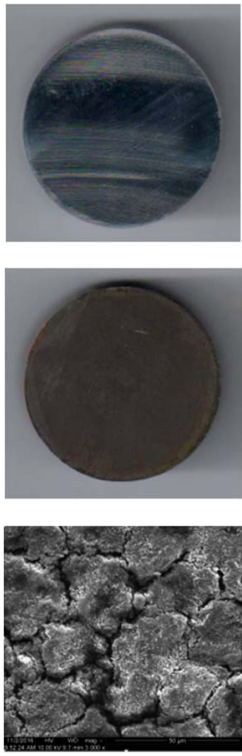
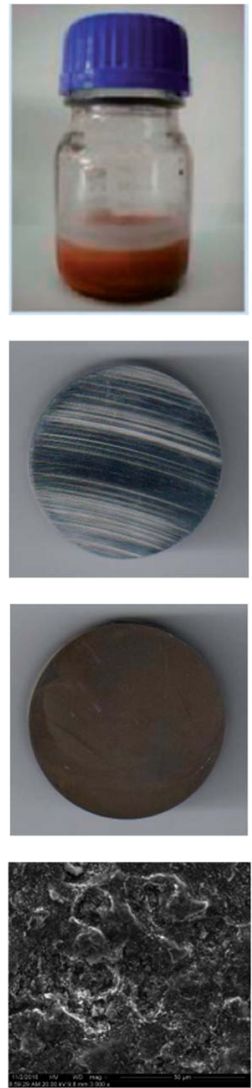
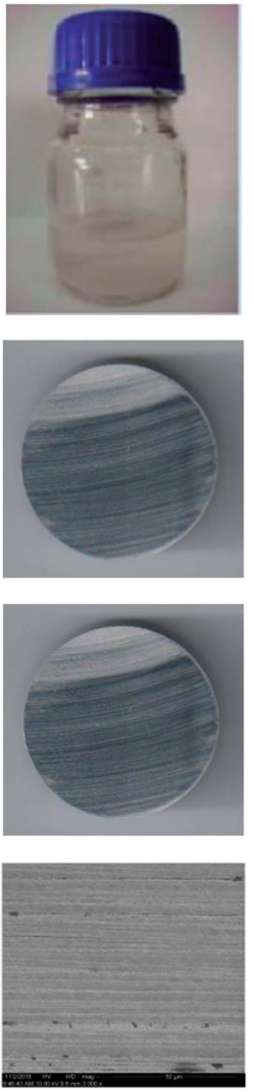
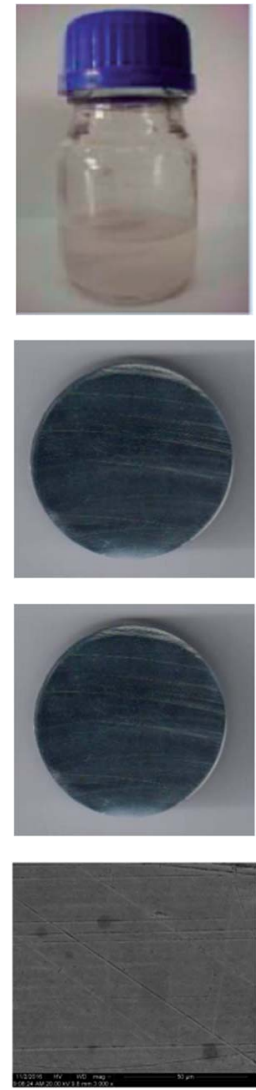
Table 5 The photographs and SEM imagines of the aluminum discs used in the accelerated corrosion tests

\begin{tabular}{lll}
\hline & Blank & $0.01 \mathrm{~mol} \mathrm{~L}^{-1} \mathrm{bmimBF}_{4} \quad 0.01 \mathrm{~mol} \mathrm{~L}^{-1} \mathrm{BTAH}^{2} \quad 0.01 \mathrm{~mol} \mathrm{~L}^{-1} \mathrm{BTAP}_{4444}$ \\
\hline Aluminium disc (before test) \\
Aluminium disc (after test)
\end{tabular}

morphologies of the aluminum discs in Table 5 also confirmed these characteristics. From Table 5, it can be seen that the aluminum disc surface socked in the blank solution is completely broken, and there are some clear pits and fault exist. The aluminum disc socked in bmimBF$_{4}$ solution is significantly blacker than those in $\mathrm{BTAH}$ and $\mathrm{BTAP}_{4444}$ solutions. The SEM morphology show that the surface has been seriously corroded, and the corrosion sediment attached to the surface resulting in the surface height changing, so the brightness of the SEM morphologies is not consistent. However, far light corrosion was found on the discs surface socked in $\mathrm{BTAH}$ and $\mathrm{BTAP}_{4444}$ solutions and protective films were formed on the surfaces. According to the above experimental data, it can be concluded that $\mathrm{BTAP}_{4444}$ has obvious anticorrosion capability for steel, copper and aluminum friction pairs when it was used as a lubricant. (a)

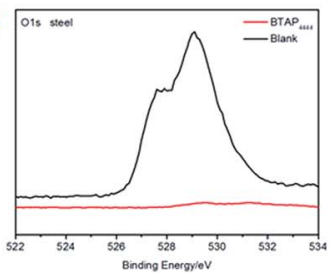

(b)

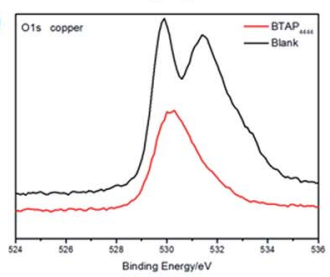

(c)

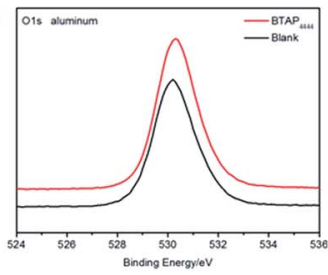

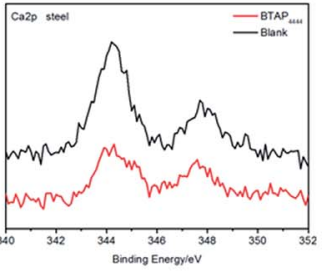
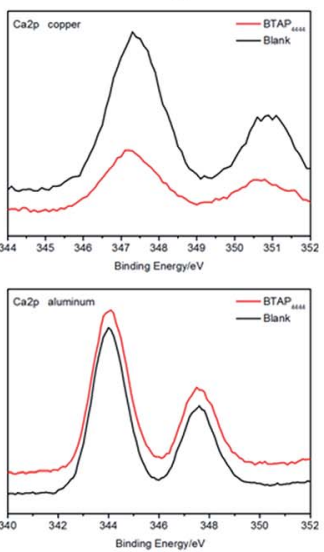
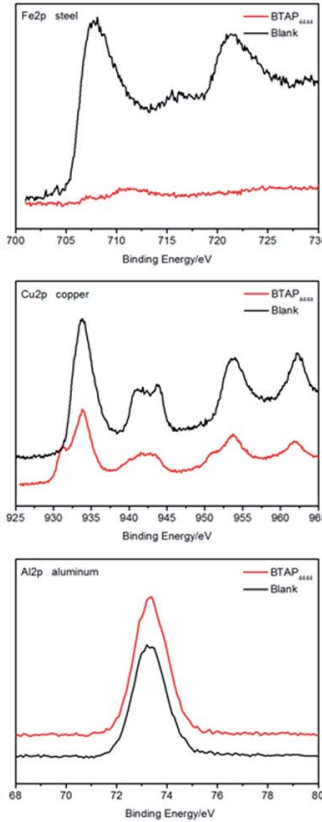
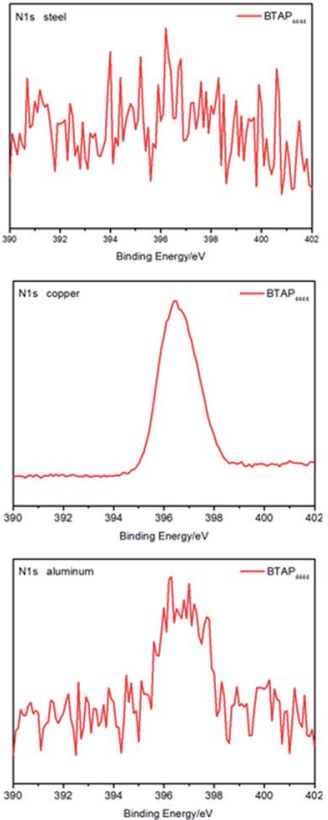

Fig. 4 The XPS spectra of the surfaces after accelerated corrosion tests (a: steel, b: copper, c: aluminum). 
3.4.3 Mechanism analysis of anti-corrosion. In order to analyze the anti-corrosion mechanism of BTAP $_{4444}$, XPS was used to analyze the surface composition of the corroded discs. The XPS spectra are shown in Fig. 4. From Fig. 4a and b, it can be clearly seen that no obvious $\mathrm{N} 1$ s and $\mathrm{P} 2 \mathrm{p}$ peaks were found on the corroded steel and aluminum discs. Only the peaks of $\mathrm{O}$ 1s, Ca $2 p$, and Fe $2 p$ could be found on these disc surfaces and their intensities were weaker than those of the corresponding peaks appeared on the blank discs. So, during the corrosion process, there is no obvious chemical reactions other than oxidation occurred on the steel and aluminium discs. Therefore, it can be speculated that the main reason of the anticorrosion property of $\mathrm{BTAP}_{4444}$ is the physical adsorption film formation between $\mathrm{BTA}^{-}$and the metal surface, which had been washed away by ultrasonic cleaning before the XPS test. Only sediment can be found on the steel and aluminium surfaces, such as $\mathrm{CaO}, \mathrm{CaCO}_{3}, \mathrm{Fe}_{3} \mathrm{O}_{4}$ and $\mathrm{FeOOH}$.

However, obvious N 1s peaks at $396.38 \mathrm{eV}$ and $396.50 \mathrm{eV}$ were found on the corroded copper surface (Fig. 4c). Combining with the $\mathrm{Cu} 2 \mathrm{p}$ peak at $932.6 \mathrm{eV}$, surface protective films composed of copper complex compounds were formed on the surface. Other than these complex compounds, $\mathrm{CuO}, \mathrm{Cu}_{2} \mathrm{O}, \mathrm{Cu}(\mathrm{OH})_{2}, \mathrm{CaO}$ and $\mathrm{CaCO}_{3}$ may be formed on the surface deducing from the characteristic peaks of $\mathrm{O} 1 \mathrm{~s}, \mathrm{Cu} 2 \mathrm{p}$ and $\mathrm{Ca} 2 \mathrm{p}$. So there were not only physical adsorption but also chemical reaction happened on the copper surface and further formed protective films to achieve the purpose of anti-corrosion. From the above results, it can be concluded that strong physical and chemical interaction between $\mathrm{BTA}^{-}$and the surface of $\mathrm{Cu}$ alloy was proposed to account for the excellent anti-wear and anti-corrosion capability of BTAP $_{4444}$.

\subsection{Friction and wear test}

The tribological properties of $\mathrm{BTAP}_{4444}$ and the reference samples PAO 10 and bmimBF$_{4}$ were studied on the above three friction pairs (steel/steel, steel/copper and steel/aluminum), which were frequently used in mechanical equipments. Fig. 5 shows the evolution of friction coefficients and wear volume losses of the sliding discs after the friction and wear test at RT. As shown in Fig. 5a, it can be seen that the friction coefficients of BTAP $_{444}$ is much lower than that of PAO 10 and a little bit higher than that of $\mathrm{bmimBF}_{4}$ on the friction pair of steel/steel. The trend of the curve is very steady and the running-in time is short enough to be ignored. From Fig. $5 b$, it can be seen that the wear volume of $\mathrm{BTAP}_{4444}$ is also far smaller than that of PAO 10 and similar to that of $\mathrm{bmimBF}_{4}$. These results confirm the good friction reducing and anti-wear properties of $\mathrm{BTAP}_{4444}$ for steel/ steel friction pair.

Under the same conditions, the tribological properties of all the samples were tested on copper and aluminum friction pairs. It was found that $\mathrm{BTAP}_{4444}$ has good lubrication performance for steel/copper and steel/aluminum friction pairs, whether in terms of friction coefficient or wear volume (Fig. 6 and 7). Comparatively speaking, PAO 10 and bmimBF $_{4}$ were found to have longer running-in times and caused serious tribocorrosion during the sliding process, especially using bmimBF$_{4}$ as
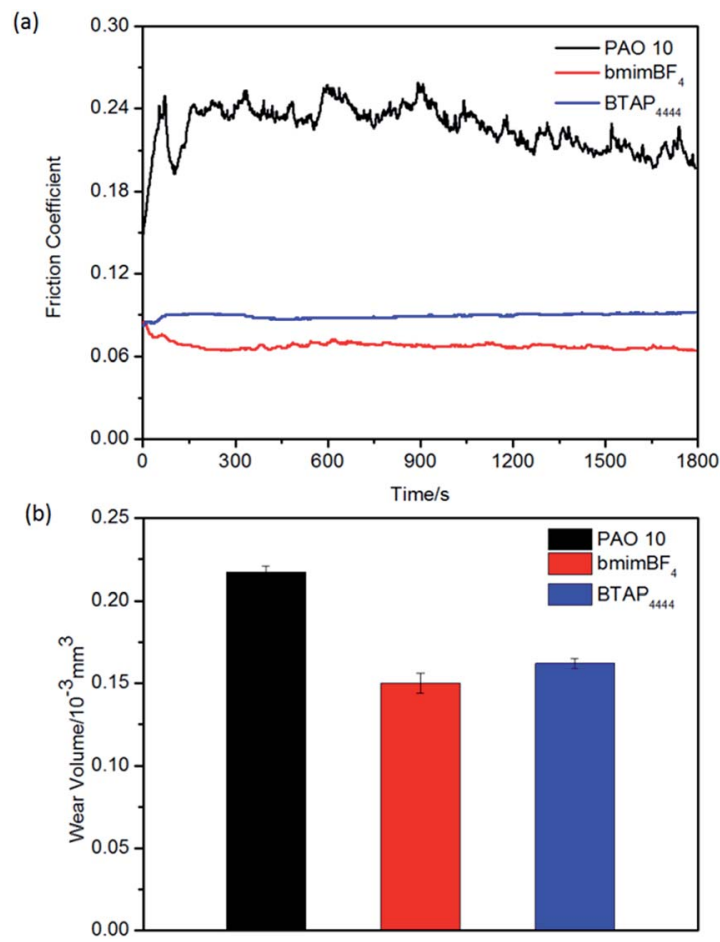

Fig. 5 Evolution of the friction coefficient (a) and wear volume losses (b) for different samples on steer/steel friction pairs at RT.

a lubricant for aluminum friction pair. On contrary, $\mathrm{BTAP}_{4444}$ has resistance to corrosion, and its friction coefficient and wear volume are far lower than those of others (Fig. 7).
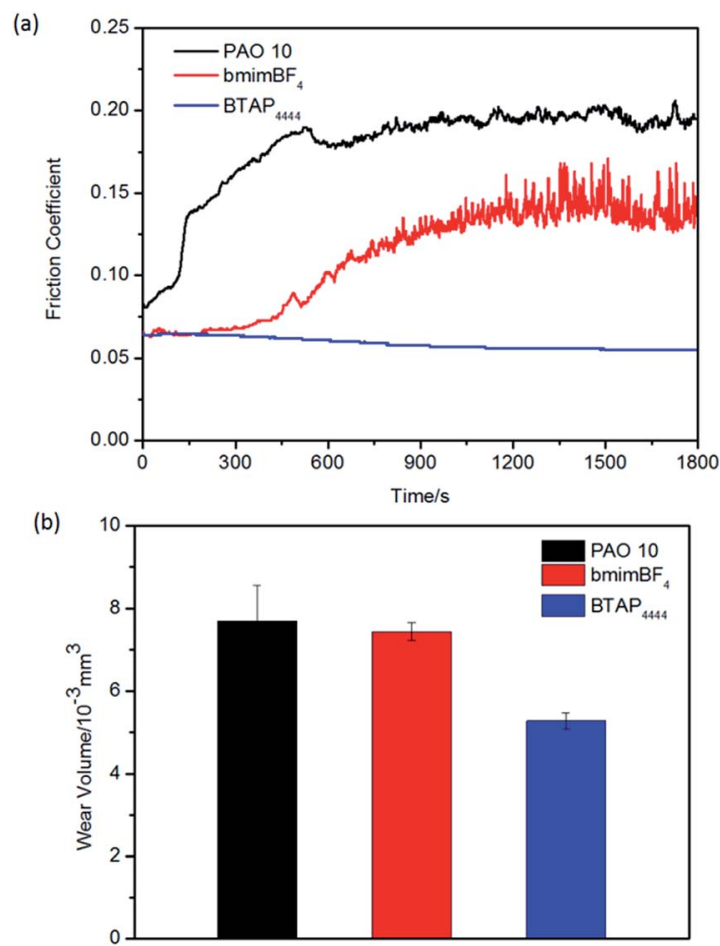

Fig. 6 Evolution of the friction coefficient (a) and wear volume losses (b) for samples on copper/steel friction pairs at RT. 
(a)

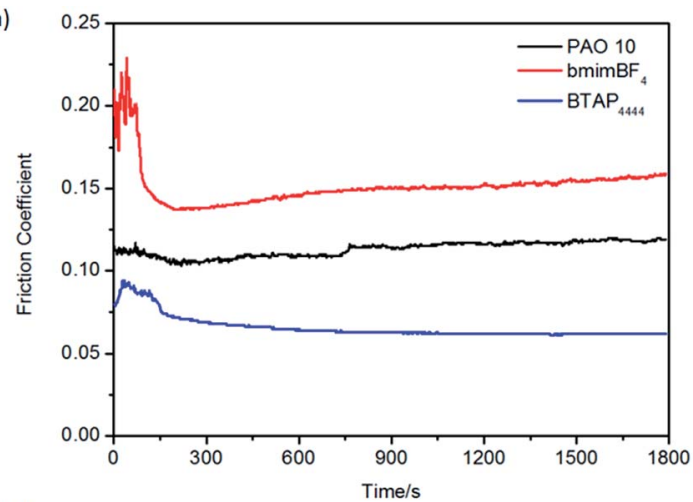

(b)

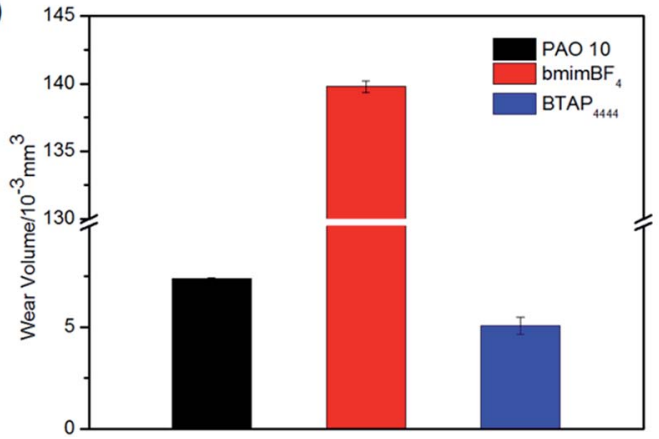

Fig. 7 Evolution of the friction coefficient (a) and wear volume losses (b) for different samples on aluminum/steel friction pairs at RT.

At the same time, we also test the tribological properties of all the samples under high temperature conditions on the above three friction pairs. The results are shown in Fig. 8-10. From the

(a)

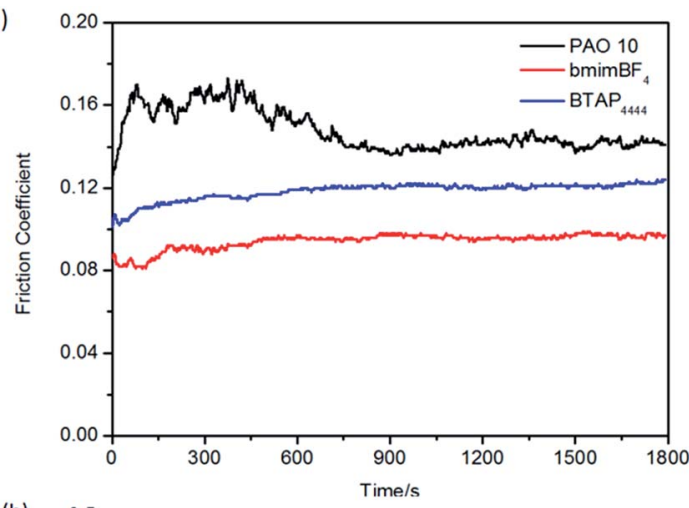

(b)

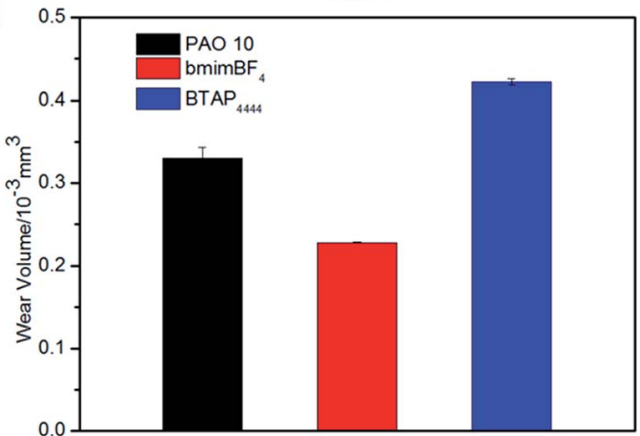

Fig. 8 Evolution of the friction coefficient (a) and wear volume losses (b) for different samples on steel/steel friction pairs at $100^{\circ} \mathrm{C}$. (a)

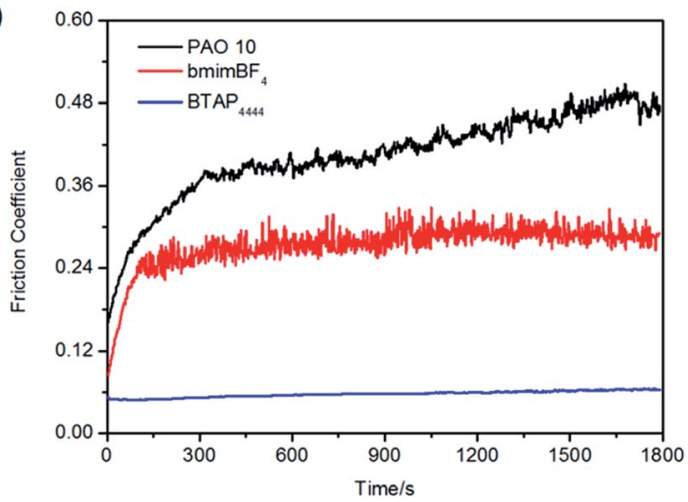

(b)

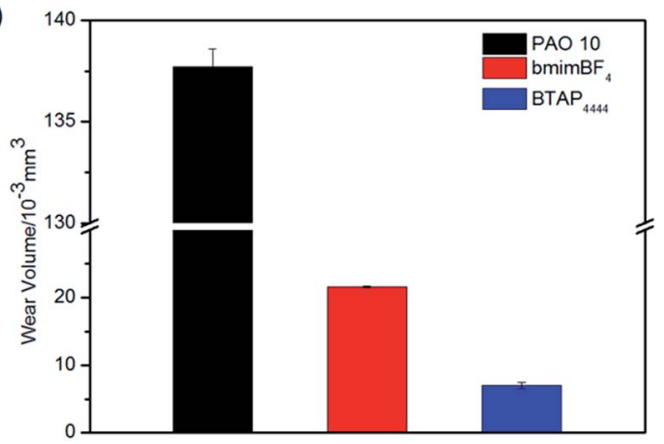

Fig. 9 Evolution of the friction coefficient (a) and wear volume losses (b) for different samples on copper/steel friction pairs at $100{ }^{\circ} \mathrm{C}$.

figures, it can be seen that $\mathrm{BTAP}_{4444}$ also has good lubrication property, especially on copper friction pairs. Both of the two comparisons have unstable and much larger friction
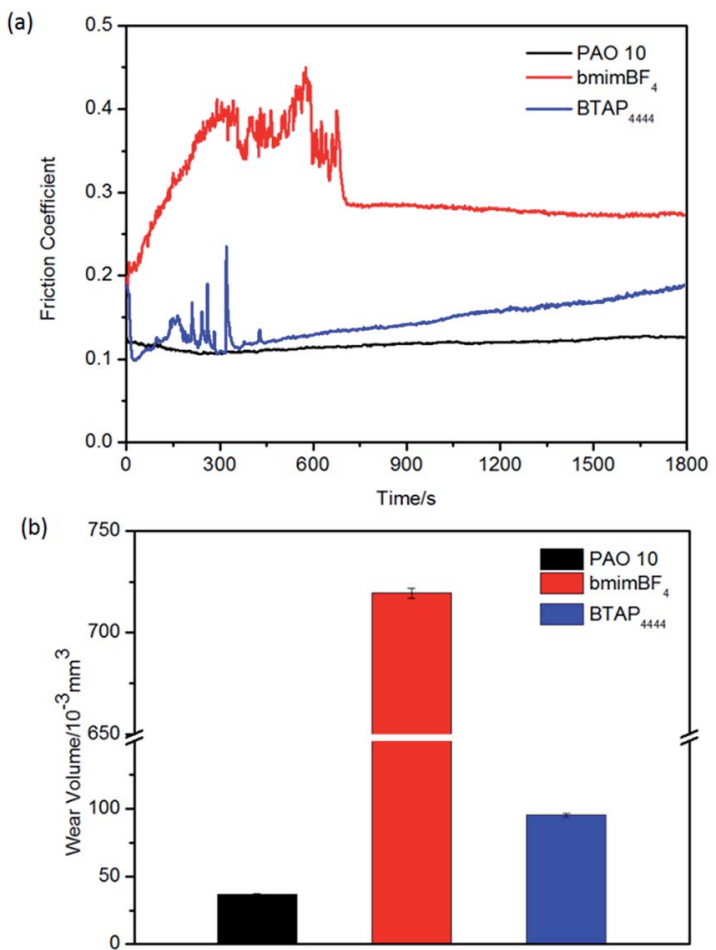

Fig. 10 Evolution of the friction coefficient (a) and wear volume losses (b) for different samples on aluminum/steel friction pairs at $100{ }^{\circ} \mathrm{C}$. 
coefficients and wear volumes. As a lubricant for copper friction pair, the friction coefficient of $\mathrm{BTAP}_{4444}$ is much lower and more stable than those of the two comparisons (Fig. 9a). From Fig. 9b, it can be seen that the wear volume of $\mathrm{BTAP}_{4444}$ is also very small, less than $1 / 15$ of PAO 10 , and just $1 / 3$ of bmimBF $_{4}$. These indicate that $\mathrm{BTAP}_{4444}$ has remarkable wear resistance at high temperature for steel/copper friction pair. It can be concluded that the functional IL $\mathrm{BTAP}_{4444}$ has excellent friction-reducing and anti-wear properties than traditional $\mathrm{IL} \mathrm{bmimBF}_{4}$. So it is more suitable to be used as a lubricant, especially at high temperature conditions.

\subsection{Mechanism analysis of friction reducing and anti-wear properties}

In order to analyze the lubricating mechanism of $\mathrm{BTAP}_{4444}$, the element composition of the worn surfaces of different friction pairs were performed by using XPS analysis data. The XPS spectra are shown in Fig. 11. It can be seen that weak $N$ 1s and $P$ $2 \mathrm{p}$ peaks were found on the spectra of the worn steel surfaces both at RT and $100{ }^{\circ} \mathrm{C}$ (Fig. 11a). It reveals that new nitride and phosphorus compound such as $\mathrm{FePO}_{4}$ and complex organic nitrogen compounds were generated on the worn surfaces during the sliding process. At the same time, combining with the peaks of $\mathrm{O} 1 \mathrm{~s}$ appearing at $530.5 \mathrm{eV}$ and $531.5 \mathrm{eV}$, other oxides such as $\mathrm{Fe}_{2} \mathrm{O}_{3}, \mathrm{Fe}_{3} \mathrm{O}_{4}, \mathrm{FeO}, \mathrm{Fe}(\mathrm{OH})_{3}$ or $\mathrm{Fe}(\mathrm{OH}) \mathrm{O}$ were formed on the worn steel surfaces. According to these results, it can be inferred that the main reason for good tribological properties of $\mathrm{BTAP}_{444}$ on steel/steel friction pair is probably attribute to the intrinsic polarity of $\mathrm{BTAP}_{4444}$ molecule to form effective physical adsorption film and further tribochemical reaction film on the sliding surfaces. ${ }^{52-54}$ These physical adsorption and tribochemical reaction films together act as effective protective films to reduce friction and wear on the steel surface.

From the Fig. 11b, it can be seen that obvious $\mathrm{N}$ 1s and $\mathrm{P} 2 \mathrm{p}$ peaks were found on the spectra of the worn copper surfaces both at RT and $100{ }^{\circ} \mathrm{C}$. Similarly, combined with the O 1 s peaks, CuO, $\mathrm{Cu}_{2} \mathrm{O}$ or $\mathrm{Cu}(\mathrm{OH})_{2}$ and other complex nitrogenous compounds may be formed on the worn copper surfaces. The $\mathrm{N}$ 1s peak at 400.4 eV can be identified as the appearing of copper complex compounds. ${ }^{55}$ At the same time, combining with the mechanism of anti-corrosion, it can be concluded that $\mathrm{BTA}^{-}$can be easily absorbed on copper surface through strong $\mathrm{N}-\mathrm{Cu}$ complexation and further react with the metal surface to form chemical adsorption and reaction films. ${ }^{56}$ These protective films provides an effective barrier layer to prevent the metal-metal contact and achieve excellent anti-wear and friction-reducing property. ${ }^{57-61}$ (a)

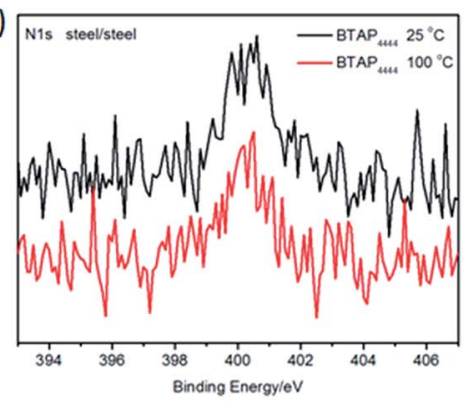

(b)

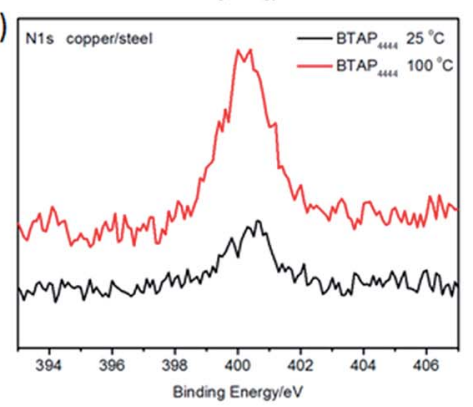

(c)

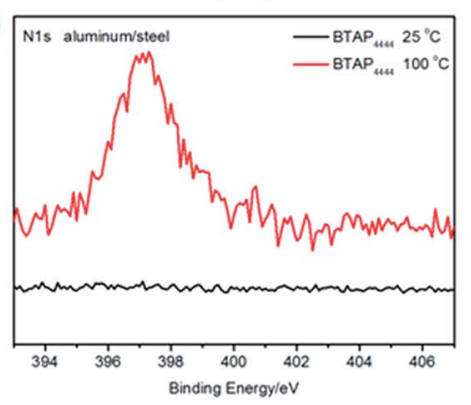

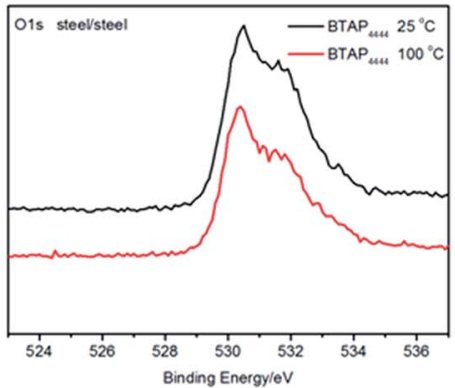
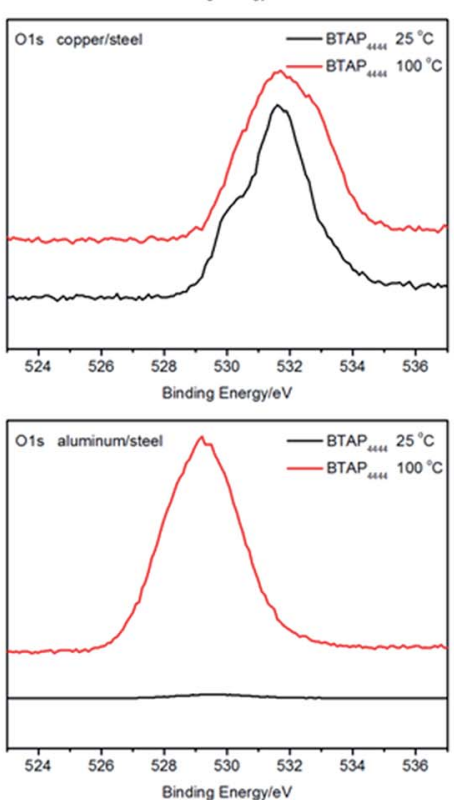
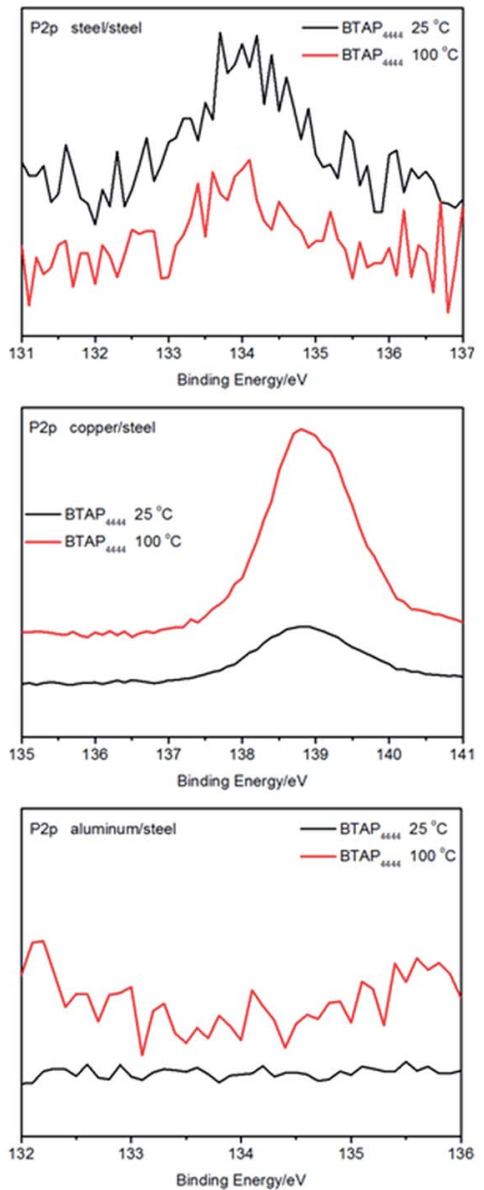

Fig. 11 The XPS spectra of the worn surfaces lubricated by BTAP 4444 at RT and $100{ }^{\circ} \mathrm{C}$ on different friction pairs (a: steel discs, b: copper discs, c: aluminum discs). 
Under the same conditions, however, no obvious $\mathrm{N}$ 1s and $\mathrm{P}$ $2 \mathrm{p}$ peaks could be found on the worn aluminum surfaces lubricated at RT and only weak $\mathrm{N}$ 1s peak can be found on the worn aluminum surface lubricated at $100{ }^{\circ} \mathrm{C}$ (Fig. 11c). Deducing from the $\mathrm{O} 1 \mathrm{~s}$ peaks, there may be $\mathrm{Al}_{2} \mathrm{O}_{3}$ appearing on the worn aluminum surfaces, but the chemical absorption and reaction of $\mathrm{BTAP}_{4444}$ with the metal surface are very weak, so the anti-wear property of $\mathrm{BTAP}_{4444}$ on aluminum surface is not strong, especially at $100{ }^{\circ} \mathrm{C}$ (Fig. 10b).

\section{Conclusions}

In this work, anti-corrosion IL BTAP $_{4444}$ was synthesized by using readily available $1 \mathrm{H}$-benzotriazole as an anion donor to react with terabutylphosphonium hydroxide. The physical and chemical properties of the IL were systematically studied and its tribological performance was tested on steel/steel, copper/steel, aluminum/steel friction pairs both at RT and $100{ }^{\circ} \mathrm{C}$. At the same time, its corrosion resistance was measured using both copper strip corrosion test and accelerated corrosion test. The results show that $\mathrm{BTAP}_{4444}$ has high thermal and hydrolytic stability, good tribological properties and high corrosion resistance to different materials. It is a new kind of anti-corrosion IL lubricant, which has good friction reducing and anti-wear properties.

\section{Acknowledgements}

We really thank the financial support from the National Natural Science Fund (51675006), an open fund of the State Key Laboratory of Solid Lubrication, Lanzhou Institute of Chemical Physics (LSL-1408), project of Science and Technology Department of Shaanxi Province (2016JZ017) and the local servicing research project of the Education Department of Shaanxi Province (15JF007). The authors would like to express our gratitude to the ILs provided by Professor Deng's group in Lanzhou Institute of Chemical Physics Chinese Academy of Sciences.

\section{Notes and references}

1 M. Rasberger, Chemistry and Technology of Lubricants, Springer, Germany, 1997.

2 C. F. Ye, W. M. Liu, Y. X. Chen and L. G. Yu, Chem. Commun., 2001, 21, 2244-2245.

3 F. Zhou, Y. M. Liang and W. M. Liu, Chem. Soc. Rev., 2009, 38, 2590-2599.

4 P. S. Bakshi, R. Gusain, M. Dhawaria, S. K. Suman and O. P. Khatri, RSC Adv., 2016, 6, 46567-46572.

5 N. V. Plechkova and K. R. Seddon, Chem. Soc. Rev., 2008, 37, 123-150.

6 T. Welton, Chem. Rev., 1999, 99, 2071-2083.

7 C. G. Venier and E. W. Casserly, Lubr. Eng., 1991, 47, 586-591.

8 M. J. Dube, D. Bollea, W. R. Jones, M. Marrcheti and M. J. Jansen, Tribol. Lett., 2003, 15, 3-8.

9 J. Q. Ma, C. J. Pang, Y. F. Mo and M. W. Bai, Wear, 2007, 263, 1000-1007.
10 Y. Wang, L. P. Wang, Y. F. Mo and Q. J. Xue, Tribol. Lett., 2011, 41, 163-170.

11 A. E. Jiménez, M. D. Bermúdez, F. J. Carrión and G. MartínezNicolás, Wear, 2006, 261, 347-359.

12 M. R. Cai, Z. Zhao, R. M. Liang, F. Zhou and W. M. Liu, Tribol. Lett., 2010, 40, 215-224.

13 B. S. Phillips and J. S. Zabinski, Tribol. Lett., 2004, 17, 533541.

14 W. M. Liu, C. F. Ye, Q. Y. Gong, H. Z. Wang and P. Wang, Tribol. Lett., 2002, 13, 81-85.

15 Y. Q. Xia, S. J. Wang, F. Zhou, H. Z. Wang, Y. M. Lin and T. Xu, Tribol. Int., 2006, 39, 635-640.

16 A. E. Jiménez, M. D. Bermúdez and P. Iglesias, Tribol. Int., 2009, 42, 1744-1751.

17 R. Gusain and O. P. Khatri, RSC Adv., 2015, 5, 2528725294.

18 A. Kokalj, S. Peljhan, M. Finšgar and I. Milošev, J. Am. Chem. Soc., 2010, 132, 16657-16668.

19 Y. Ma, F. Han, Z. Li and C. G. Xia, ACS Sustainable Chem. Eng., 2016, 4, 633-639.

20 Z. H. Song, Y. M. Liang, M. J. Fan, F. Zhou and W. M. Liu, RSC Adv., 2014, 4, 19396-19402.

21 Y. Kondo, T. Koyama, R. Tsuboi, M. Nakano, K. Miyake and S. Sasaki, Tribol. Lett., 2013, 51, 243-249.

22 F. U. Shah, S. Glavatskih, D. R. MacFarlane, A. Somers, M. Forsyth and O. N. Antzutkin, Phys. Chem. Chem. Phys., 2011, 13, 12865-12873.

23 V. Totolin, I. Minami, C. Gabler and N. Dorr, Tribol. Int., 2013, 67, 191-198.

24 R. Gusain, R. Singh, K. L. N. Sivakumar and O. P. Khatri, RSC Adv., 2014, 4, 1293-1301.

25 R. Gusain, P. Gupta, S. Saran and O. P. Khatri, ACS Appl. Mater. Interfaces, 2014, 6, 15318-15328.

26 R. Gusain, P. Gupta, S. Saran and O. P. Khatri, Ind. Eng. Chem. Res., 2016, 55, 856-865.

27 Procter and L. Gamble, Br. Pat., 652339, 1947.

28 R. Walker, J. Chem. Educ., 1980, 57, 789-791.

29 H. Brinch Madsen, Stud. Conserv., 1967, 12, 163-167.

30 H. Brinch Madsen, Stud. Conserv., 1971, 16, 120-122.

31 J. J. Kim, S. K. Kim and J. U. Bae, Thin Solid Films, 2002, 415, 101-107.

32 F. E. T. Heakal and S. Haruyama, Corros. Sci., 1980, 20, 887898.

33 A. Ababneh, M. Sheban and M. Abu-Dalo, J. Mater. Civ. Eng., 2012, 24, 141-151.

34 D. Gopi, K. M. Govindaraju, V. Collins Arun Prakash, D. M. Angeline Sakila and L. Kavitha, Corros. Sci., 2009, 51, 2259-2265.

35 D. Gopi, K. M. Govindaraju, V. Collins Arun Prakash, V. Manivannan and L. Kavitha, J. Appl. Electrochem., 2009, 39, 269-276.

36 A. D. Modestov, G. D. Zhou, Y. P. Wu, T. Notoya and D. P. Schweinsberg, Corros. Sci., 1994, 36, 1931-1946.

37 C. Verma, P. Singh, I. Bahadur, E. E. Ebenso and M. A. Quraishi, J. Mol. Liq., 2015, 209, 767-778.

38 N. Soltani, M. Behpour, E. E. Oguzie, M. Mahluji and M. A. Ghasemzadeh, RSC Adv., 2015, 5, 11145-11162. 
39 C. Verma, L. Olasunkanmi, I. B. Obot and M. A. Quraishi, RSC Adv., 2016, 6, 1-52.

40 M. M. Antonijevic and M. B. Petrovic, Int. J. Electrochem. Sci., 2008, 3, 1-28.

41 M. Finšgar and I. Milošev, Corros. Sci., 2010, 52, 2737-2749.

42 X. Liu, F. Zhou, Y. M. Liang and W. M. Liu, Tribol. Lett., 2006, 23, 191-196.

43 M. R. Cai, R. M. Liang, F. Zhou and W. M. Liu, ACS Appl. Mater. Interfaces, 2011, 3, 4580-4592.

44 Z. H. Song, M. R. Cai, Y. M. Liang, M. J. Fan, F. Zhou and W. M. Liu, RSC Adv., 2013, 3, 21715-21721.

45 M. J. Fan, D. S. Yang, X. L. Wang, W. M. Liu and H. Z. Fu, Ind. Eng. Chem. Res., 2014, 53, 17952-17960.

46 M. J. Fan, X. L. Wang, D. S. Yang, D. M. Wang, Y. Y. Yan, c. Y. Zhang and X. C. Liu, Tribol. Int., 2015, 92, 344-352.

47 R. R. Sahoo and S. K. Biswas, J. Colloid Interface Sci., 2009, 333, 707-718.

48 C. J. Reeves, P. L. Menezes, T. C. Jen and M. R. Lovell, Tribol. Int., 2015, 90, 123-134.

49 G. R. Yu, D. C. Zhao, L. Wen, S. D. Yang and X. C. Chen, AIChE J., 2012, 58, 2885-2899.

50 S. Seki, T. Kobayashi, Y. Kobayashi, K. Takei, H. Miyashiro, K. Hayamizu, S. Tsuzuki, T. Mitsugi and Y. Umebayashi, J. Mol. Liq., 2010, 152, 9-13.
51 K. Tsunashima and M. Sugiya, Electrochem. Commun., 2007, 9, 2353-2358.

52 Z. B. Zhou, H. Matsumoto and K. Tatsumi, Chem.-Eur. J., 2006, 12, 2196-2212.

53 J. Qu, P. J. Blau, S. Dai, H. Luo and H. M. Meyer III, Tribol. Lett., 2009, 35, 181-189.

54 R. T. Haasch, T. Y. Lee, D. Gall, J. E. Greene and I. Petrov, Surf. Sci. Spectra, 2000, 7, 204-212.

55 http://srdata.nist.gov/xps/.

56 Y. Jiang and J. B. Adams, Surf. Sci., 2003, 529, 428-442.

57 C. Verma, L. O. Olasunkanmi, I. B. Obot, E. E. Ebenso and M. A. Quraishi, RSC Adv., 2016, 6, 15639-15654.

58 D. G. Shchukin, S. V. Lamaka, K. A. Yasakau, M. L. Zheludkevich, M. G. S. Ferreira and H. Möhwald, J. Phys. Chem. C, 2008, 112, 958-964.

59 V. Palanivel, Y. Huang and W. J. van Ooij, Prog. Org. Coat., 2005, 53, 153-168.

60 D. Raps, T. Hack, J. Wehr, M. L. Zheludkevich, A. C. Bastos, M. G. S. Ferreira and O. Nuyken, Corros. Sci., 2009, 51, 10121121.

61 M. Garcia-Heras, A. Jimenez-Morales, B. Casal, J. C. Galvan, S. Radzki and M. A. Villegas, J. Alloy. Compd., 2004, 380, 219224. 